\title{
Intoxicación por superwarfarinas
}

\section{Superwarfarins poisoning}

Patricia Crecente Otero, Jorge Luis Torres Triana, Ronald Macías Casanova, Luis Manuel Sánchez Rodríguez

Servicio de Medicina Interna. Hospital Clínico Universitario de Salamanca

\section{Introducción}

Las denominadas superwarfarinas se desarrollaron a partir de la década de 1970 como solución a las resistencias que habían desarrollado los roedores a los raticidas hasta entonces existentes ${ }^{1}$. Sus principales ventajas son su mayor potencia (hasta 100 veces más potentes que la warfarina) ${ }^{2} \mathrm{y}$ el disponer de una semivida más larga (hasta 6-8 semanas). Presentamos el caso de un paciente varón que ingresa en nuestro servicio de Medicina Interna por otorragia y hematuria para estudio. Como único antecedente es consumidor ocasional de cocaína inhalada. Se confirma la intoxicación por un potente raticida, la bromadiolona.

\section{Caso clínico}

Paciente varón de 34 años que acudió al Servicio de Urgencias por otorragia derecha persistente tras traumatismo local leve con un bastoncillo higiénico los días previos, además de hematuria de una semana de evolución. Como único antecedente era consumidor ocasional de cocaína inhalada. No seguía ningún tratamiento en el momento de la consulta. El paciente se encontraba hemodinámicamente estable y la exploración física por aparatos era anodina, a excepción de una pequeña perforación timpánica sangrante. En la analítica realizada en urgencias presentaba una bioquímica con un perfil renal y hepático normal, PCR: 0,10 mgr/dl, hemoglobina: 15,4 g/dl, Plaquetas: 173000/ul. y hemoglobina en orina de cuatro cruces. En el estudio de hemostasia y trombosis destacaba un tiempo de protrombina (TP): 5\%, tiempo parcial de tromboplastina activa (TTPA): 117,3 seg y un INR: 16,26. Ingresó a cargo de nuestro servicio de Medicina Interna para estudio de coagulopatía.

En planta se inició tratamiento con vitamina $\mathrm{K}$, inicialmente intravenoso (30 mg/d) durante 4 días, hasta la corrección en los valores de coagulación. Tras la suspensión del mismo se objetivaron nuevamente valores anormales en los parámetros de coagulación, con un INR de 9, que nos obligó a reintroducir el tratamiento de forma intravenosa durante una semana y posteriormente por vía oral $(30 \mathrm{mg} / \mathrm{d})$ una semana más, permaneciendo desde entonces el paciente asintomático y sin signos de sangrado activo. Se completó el análisis con estudio de hepatopatía, marcadores tumorales, proteinograma y autoinmunidad, estando todos los valores dentro de la normalidad. En el estudio de hemostasia y trombosis ampliada destacaba un importante descenso de los factores de coagulación II, VII, IX y X (8\%, 5\%, 5\% y 8\% respectivamente. Valor de referencia: $60-120)$ todos ellos dependientes de vitamina K. Las pruebas de imagen: radiografía de tórax y abdomen y ecografía abdominal son normales.
Se sospechó una intoxicación por anticoagulantes orales. El paciente negó en todo momento consumo accidental o voluntario de algún tipo de anticoagulante. Como único antecedente refería ser consumidor de cocaína inhalada. La valoración psiquiátrica fue normal. Se remitió una muestra de sangre al laboratorio de referencia en Madrid para examen toxicológico que informó de la presencia de un potente anticoagulante existente en los raticidas, la bromadiolona. Una segunda muestra que confirmó el resultado inicial, el cual explicaría la sintomatología que presentaba el paciente.

Se decidió mantener el tratamiento con vitamina $\mathrm{K}$ vía oral con 10 $\mathrm{mgr} / \mathrm{d}$ de forma ambulatoria durante dos meses, con controles analíticos semanales, con buen cumplimiento terapéutico y evolución clínica.

\section{Discusión}

En el Registro Oficial de Plaguicidas de Uso en Salud Pública en España están registrados 11 Ingredientes Activos Técnicos (IAT) para la formulación de rodenticidas, de los cuales 9 son anticoagulantes, 1 produce hipercalcemia y 1 tiene acción sedativa ${ }^{3}$. En la tabla 1 se recoge su grado de toxicidad, en función del principio activo y la concentración empleada.

Las superwarfarinas producen su efecto tóxico al inhibir las enzimas vitamina K2,3-epóxido reductasa y vitamina $K$ quinona reductasa, impidiendo la activación de la vitamina $\mathrm{K}$ y, secundariamente, la de los factores de coagulación dependientes de ésta (II, VII, IX, X, proteína C y proteína S) sintetizados en el hígado. Esto se traduce en un alargamiento del TP. Las manifestaciones clínicas varían según la dosis ingerida y el tiempo de exposición. Aunque la mayoría de los casos cursan sin ninguna sintomatología, por tratarse de intoxicaciones accidentales con dosis bajas, en otros casos, con sobredosis o exposiciones crónicas, aparecen signos de sangrado como equimosis, epixtasis, hematemesis, hematuria, hemoptisis, melenas, petequias, sangrado vaginal 0 incluso la muerte por afectación de varios órganos o sistemas ${ }^{4}$. Ante un paciente que presenta coagulopatía de etiología incierta y prolongada, signos de sangrado y disminución de factores de coagulación dependientes de vitamina $\mathrm{K}$ siempre hay que sospechar este diagnóstico ${ }^{5,6}$.

La cocaína es un estimulante del sistema nervioso central y simpático que provoca efectos eufóricos, casi idénticos a los que produce la anfetamina y la adrenalina. La cocaína 
vendida en las calles en forma de polvo blanco, fino y cristalino, contiene entre 4 a 10\% de cocaína pura, mezclada con otros ingredientes de origen y composición dudosa: harina, talco, cal, azúcar anfetaminas, procaína, benzocaína, vidrio o raticida ${ }^{7}$. La mezcla de droga con veneno y otras sustancias de uso industrial y comercial es estrategia de moda entre los narcotraficantes para masificar la demanda y aumentar sus ganancias ${ }^{7}$. En ocasiones, la mezcla de cocaína y raticida es voluntaria, para potenciar más los efectos eufóricos de la droga. Habitualmente se emplea aspirándola, aunque hay quienes recurren a la inyección endovenosa, porque el efecto es más rápido y duradero; pero aumenta la dependencia y el peligro. Los últimos estudios realizados revelan que la mayor parte de lo que se vende hoy en día no es solo cocaína, sino una combinación de varios productos. Aunque esta combinación no ha sido confirmada en nuestro paciente, la sospecha diagnóstica es alta tras excluir otras causas de sobredosificación por warfarinas y porque la adulteración y combinación de drogas ilícitas con raticidas comienza a ser un fenómeno creciente.

El tratamiento y antídoto, es con suplementos de vitamina $\mathrm{K}_{1}$ (fitonadiona), ya que las vitaminas $\mathrm{K}_{3}$ (menadiona) 0 la vitamina $\mathrm{K}_{4}$ (menadiol) no se consideran antídotos para estos anticoagulantes. Se pueden requerir hasta 40mgr/Kg/día (en 3-5 dosis), con monitorización del TP para confirmar su normalización, y durante un tiempo prolongado dado que las superwarfarinas son sustancias lipofílicas acumulables en el organismo y con una vida media de semanas o meses. Si existe sangrado activo se valorará la transfusión de concentrados de hematíes y factores de coagulación. La monitorización de las concentraciones de superwarfarinas en sangre a las 48 horas de la primera determinación y en determinaciones sucesivas puede ser útil para decidir cuándo concluir el tratamiento. ${ }^{4}$
Tabla 1: Clasificación Toxicológica de los diferentes productos registrados con efecto rodenticidas

\begin{tabular}{|c|c|c|c|c|}
\hline Ingrediente Activo Técnico* & $\mathrm{N}$ & $\mathrm{T}$ & MT & Total \\
\hline Rodenticidas anticoagulantes & 24 & 14 & 27 & 65 \\
\hline A - Cumarínicos & 18 & 12 & 21 & 51 \\
\hline 1 - Bromadiolona & 10 & 3 & 6 & \\
\hline 2 - Brodifacum & 2 & 4 & 5 & \\
\hline 3 - Difenacoum & 6 & 1 & 5 & \\
\hline 4 - Warfarina & - & 4 & 1 & \\
\hline 5 - Difetialona & - & - & 2 & \\
\hline 6 - Cumatetralilo & - & - & 1 & \\
\hline 7 - Flocoumafen & - & - & 1 & \\
\hline B - Inandiónicos & 5 & 2 & 5 & 12 \\
\hline \multirow{2}{*}{$\begin{array}{l}8 \text { - Clorafacinona } \\
9 \text { - Difacinona }\end{array}$} & 5 & 2 & 4 & \\
\hline & - & - & 1 & \\
\hline Otros: & 1 & - & 1 & 2 \\
\hline 10- Colecalciferol & - & & 1 & \\
\hline 11- Alfacloralosa & 1 & - & - & \\
\hline
\end{tabular}

*Ingrediente activo técnico: N nocivo; T tóxico; MT muy tóxico

\section{Bibliografía}

1. Beriain M, Gómez B, Benito J y Mintegi S. Ingesta accidental de superwarfarinas Anales de Pediatría. (Barcelona).2008; 68(5):503-6

2. Zhao S, Li P, Ji M, Zong Y, Zhang S. Upper gastrointestinal hemorrhage caused by superwarfarin poisoning. World J Gastroenterol. 2010; 16(13):1680-82

3. Moreno MJ, López Ferrer J, Jiménez Peydró R. El control de los roedores: revisión de los rodenticidas registrados en el ámbito de la sanidad ambiental en España. Revista Española Salud Pública. 2004; 78:5-16.

4. Dolin E, Baker D, Buck S. A 44-year-old woman with hematemesis and cutaneous hemorrhages as a result of superwarfarin poisoning. Case Report. J Am Osteopath Assoc. 2006;106(5): 280-4

5. Spahr JE, Maul JS, Rodgers GM. Superwarfarin poisoning: a report of two cases and review of the literature. Am J Hematol. 2007; 82: 656-60

6. Gunja N, Coggins A, Bidny S. Management of intentional superwarfarin poisoning with long-term vitamina $\mathrm{K}$ and brodifacum levels. Clinical Toxicology. 2011; 49(5):385-90

7. Blancas Madrigal, D. Adulterar coca, moda de comercializadores. (2008-06-01).La Crónica de Hoy. Recuperado el 10 de Noviembre de 2011 del sitio Web http://www. cronica.com.mx 